\title{
Pure Waterjet Drilling of Articular Bone: An in vitro Feasibility Study
}

\author{
Steven den Dunnen ${ }^{1 *}$ - Gert Kraaij ${ }^{1,4}$ - Christian Biskup ${ }^{3}$ - Gino M.M.J. Kerkhoffs 2 - Gabrielle J.M. Tuijthof ${ }^{1,2}$ \\ ${ }^{1}$ Delft University of Technology, Department of Biomechanical Engineering, The Netherlands \\ ${ }^{2}$ Academic Medical Center, Department Orthopedic Surgery, The Netherlands \\ 3 (formerly) Leibniz University Hannover, Institute of Materials Science, Germany \\ ${ }^{4}$ Leiden University Medical Center, Department Orthopaedics, The Netherlands
}

The clinical application of waterjet technology for machining tough human tissues, such as articular bone, has advantages, as it produces clean sharp cuts without tissue heating. Additionally, water supply is possible via flexible tubing, which enables minimally invasive surgical access. This pilot study investigates whether drilling bony tissue with pure waterjets is feasible.

Water pressures between 20 and $120 \mathrm{MPa}$ with an orifice of $0.6 \mathrm{~mm}$ were used to create waterjets to drill blind borings in the talar articular surface of cadaveric calcaneus bones of human, sheep, goats and pigs. A stand-off distance between 2.5 and $5.5 \mathrm{~mm}$ and a jet-time of 5 seconds were chosen. The depth of the holes was measured using a custom-adapted dial gauge.

At least $30 \mathrm{MPa}$ of water pressure is required to penetrate the human and goat specimens, and $50 \mathrm{MPa}$ for the pig and sheep specimens. Overall, the machined holes were conically shaped and increased in depth with an increase of pressure. Above certain pressure levels, pure waterjets can be used for machining holes in articular bone, thereby opening a window for further research on pure waterjet drilling in orthopedics.

Keywords: pure water jet, water jet drilling, drilling articular bone, orthopedic treatment, water pressure

\section{O INTRODUCTION}

Since its first successful application in the 1970s by Hashish, waterjet technology has been applied in many industries [1] such as cutting cardboard, metals and frozen food [2] and [3]. For medical applications, differences in the material properties of human organs allow the precise dissection of soft tissue without damaging stronger tissues such as nerves or veins [4] to [6]. The absence of tissue heating [7] and the always sharp and clean cut, in particular, has led to the further exploration of waterjet technology for applications in orthopedic surgery [8] to [13]. Research in this has field primarily involved cutting cortical bone with abrasive (containing small solid particles) waterjets for preparation for arthroplasty [8] to [10] and [13] to [15].

Additionally, using waterjet technology allows for water supply via flexible tubing, which enables minimally invasive surgical access. The focus of this study will be on the latter application, for which it is necessary to investigate the feasibility of pure waterjets to drill holes in articular bone. Drilling holes in bones is frequently performed in, for example, microfracturing treatments and screw fixations [16] and [17]. Knowledge from previous studies cannot be used to determine the feasibility of pure waterjet drilling in articular bone, as this differs entirely from abrasive waterjet cutting. The differences lie in the interaction between the waterjet and the material, which causes the penetration depth using pure waterjet drilling to be less than for abrasive waterjet cutting. When cutting, the waterjet is moved over the material with a set feed speed (Fig. 1). The waterjet first strikes the edge of the material and exits at the opposite side. When drilling, the waterjet does not continue its path through all the material, but changes its trajectory 180 degrees after reaching the bottom of the hole (Fig. 1) [18] and [19]. Therefore, interference with the incoming waterjet is inevitable [2] and [3]. This leads to a disruption of the integrity of the waterjet and a turbulent flow in the boring, causing the impact pressure and kinetic energy to diminish [2], [18] and [20].

To improve the cutting capacity of water jets, previous research involved the addition of abrasives to the waterjet [21]. Special biocompatible abrasives have been proposed and tested in a lab settings [8] and [15], but thus far no clinical trials have been performed to verify their safe use. Other than that, articular bone toughness is presumably less than that of diaphyseal cortical bone. Therefore, an abrasive suspension might not be necessary in order to penetrate the articular bone. Pure waterjets are investigated in this study, because they contribute to patients' safety.

The aim of this study is to determine the feasibility of pure waterjet drilling in articular bone, and indicate the minimum water pressure required to penetrate articular bone. The sub-goals are: a) determination of the variation in the minimum penetration pressure. 
This variation can also be expected amongst the patients receiving surgical treatment and is therefore of concern for patient safety; b) global analysis of the shape of holes in bone, because specific hole profiles are desired for certain orthopedic treatments.

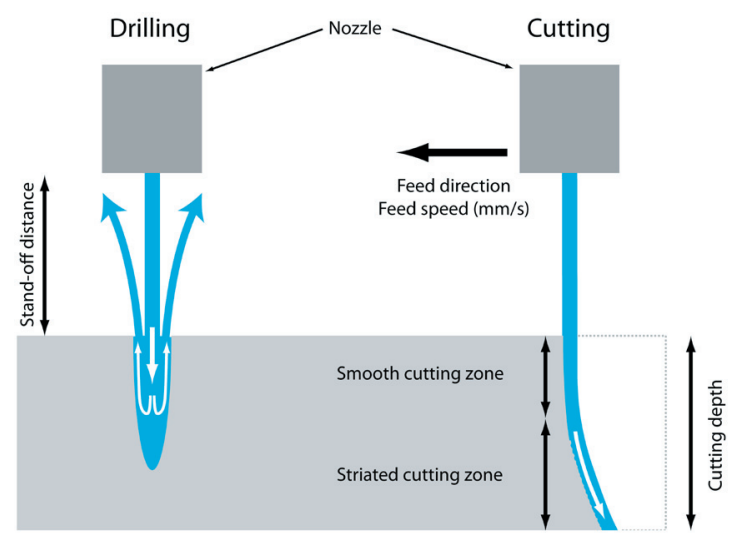

Fig. 1. The difference in waterjet flow direction between waterjet drilling and cutting

\section{MATERIALS AND METHODS}

A theoretical overview is established regarding a) the main parameters that influence the machining capacity of a pure waterjet, and b) the expected consecutive steps of the waterjet-material interaction when drilling a hole in articular bone. Based on this, starting conditions for the pilot study were chosen, and interpretations of the results were facilitated.

In addition to the mechanical properties of the material, the two dominant parameters for the machining capacity of a waterjet are the velocity and the volume of the water that is striking the object [2]. An increase in either one of these parameters will increase the kinetic energy of the waterjet, which is transferred to the material on impact. Assuming water is incompressible, the relation between the waterjet velocity $v_{\text {liquid }}[\mathrm{m} / \mathrm{s}]$ and the water pressure $P\left[\mathrm{~N} / \mathrm{m}^{2}\right]$ and density $\rho\left[\mathrm{kg} / \mathrm{m}^{3}\right]$ is given by Bernoulli's equation:

$$
v_{\text {liquid }}=\mu v \cdot \sqrt{\frac{2 P}{\rho}} .
$$

The velocity coefficient $\mu_{v}$ depends on the waterjet setup that is used, but is usually between 0.86 and 0.97 [22]. As the $\mu_{v}$ and $\rho$ remain constant, the waterjet velocity is dependent solely on the water pressure. Therefore, varying the pressure was chosen.

When drilling in articular bone, the waterjet needs to penetrate cartilage, subchondral bone and trabecular bone, consecutively. Each layer has a specific composition and material properties [23]. The mechanical properties that play a significant role in the effectiveness of waterjet machining are, in order of importance, the tensile strength, compressive strength, modulus of elasticity and hardness [3]. An increase in any of these properties will increase the strength of the material and thus the resistance to a waterjet. The tensile strength at the tissue level for articular cartilage, cortical bone and trabecular bone in human femora are approximately $30 \mathrm{MPa}$ [24], $120 \mathrm{MPa}$ [25] and [26] and $20 \mathrm{MPa}$ [27] and [28], respectively. Even though these numbers alone cannot be used to predict whether a waterjet can penetrate the bone tissue, the subchondral bone layer will most likely offer the highest resistance.

The cartilage is expected to be machined the most easily as the modulus of elasticity and the hardness is lower than for trabecular bone [26] and [29]. In summary, the feasibility of drilling articular bone with pure water greatly relies on the ability to penetrate the subchondral plate. Increasing the water pressure will increase the waterjet's ability to penetrate this bone layer.

Waterjet drilling of bony tissue was performed on an industrial waterjet cutting system (Fig. 2a) equipped with a high-pressure intensifier pump DU 400-4/PL. The cutting table was controlled by a Berger Lahr NC control system (Posab 3300), which also regulated the waterjet time.

A waterjet nozzle diameter (Fig. 2b) of 0.6 $\mathrm{mm}$ and a jet time of five seconds was used in all experiments. The diameter of the machined holes created by this nozzle were most comparable to the $1.3 \mathrm{~mm}$ diameter holes that are frequently created in orthopedic microfracturing. Based on the experiments of Honl et al. [10], the water pressure was varied between 20 and $120 \mathrm{MPa}$. The genuine pressure was measured directly in front of the water jet cutting head at a sample frequency of $50 \mathrm{~Hz}$ with a WIKA high pressure transducer (type 891.23.610).

Fresh frozen calcanei of four mammals were obtained: five goat, six sheep, four pig and five human bones. The animals were chosen as they are frequently used for orthopedic animal-experiments due to their similar weight, metabolism [30] and [31] and bone volume fraction [32] to [34] as humans. The specimens were removed from frozen storage 30 minutes before the experiment and sprinkled with a $0.9 \%$ saline solution, thereby preserving the cartilage tissue and allowing the bone to come to room temperature before waterjet drilling. To prevent collision with the waterjet nozzle, protrusions were sawed off (Fig. 2c). 


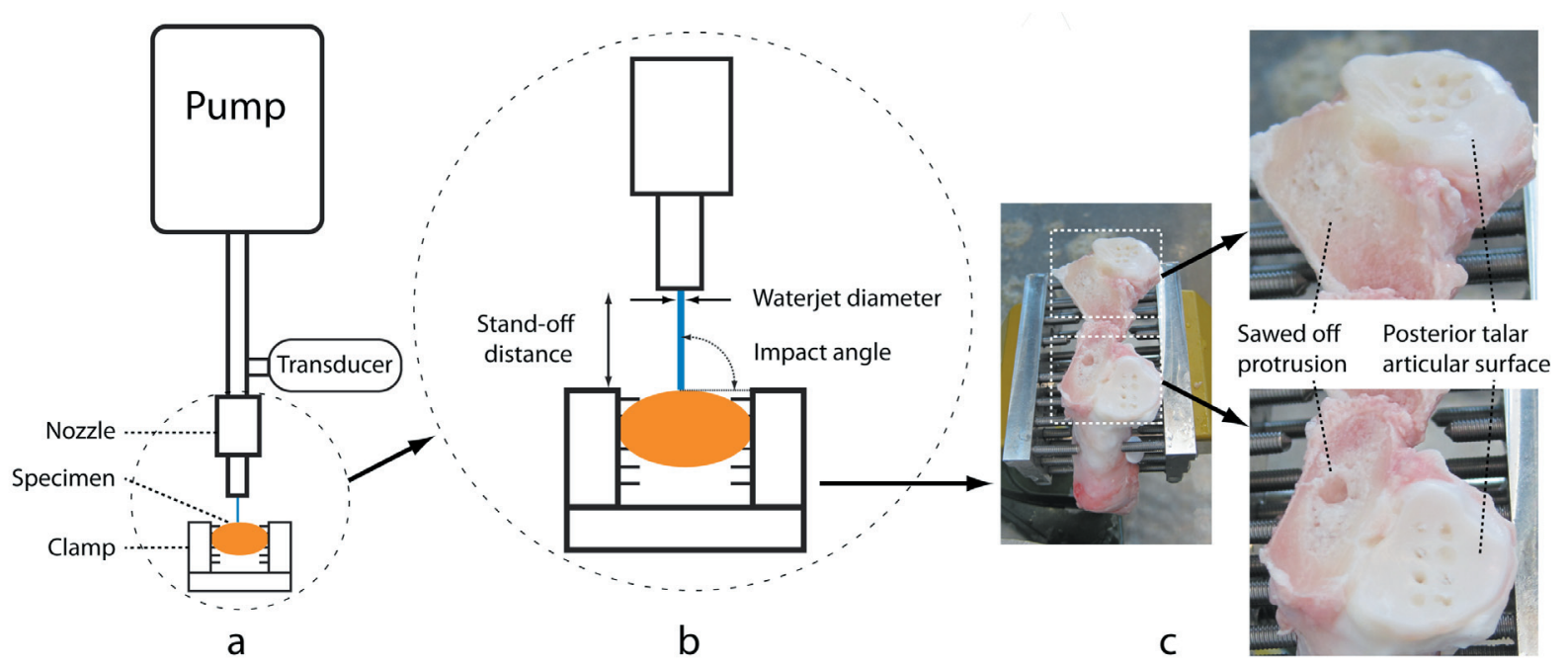

Fig. 2. a) overview of the experimental setup, b) potential waterjet settings, c) two bone specimens fixated in a clamp

Holes were drilled in the posterior articular facet of the calcanei, at least $5 \mathrm{~mm}$ from the rim of the surface area to prevent drilling in cortical bone (Fig. 2c). A specially adapted clamp allowed for perpendicular alignment of the bone surface and the waterjet. Individually adjustable pins at the sides of the clamp provided a firm grip on the specimens (Fig. 2c). To prevent location-based bias, holes were machined in a random order of sequence per calcaneus. Depending on the size of the articular surface, six to nine holes were drilled at least $4 \mathrm{~mm}$ apart in each specimen. As perpendicular drilling enables the deepest cuts in cortical bone drilling [10], an impact angle of 90 degrees was used for all experiments (Fig. 2b). The stand-off distance between the nozzle and the specimen was set at $3 \mathrm{~mm}$, using a spacer. In practice, this led to a stand-off distance between 2.5 and $5.5 \mathrm{~mm}$ due to the curved articular surface of the bones.

The depth of the machined blind holes was measured with a dial-gauge [18]; the standard $1 \mathrm{~mm}$ wide sensory tip was replaced by a $0.3 \mathrm{~mm}$ wide tip made out of pivot steel wire. The adaptation increased the measurement depth to $30 \mathrm{~mm}$ and decreased the minimum required hole diameter. The $0.3 \mathrm{~mm}$ tip was small enough to reach the bottom of the holes, but could not enter natural cavities in the undrilled trabecular bone. To prevent the trabecular bone from being damaged by the wire, the insertion force was kept between 0.2 and $0.3 \mathrm{~N}$ by using a spring. Three measurements were performed on each hole, and a re-measurement was performed if the variation was larger than $0.25 \mathrm{~mm}$.
The cartilage thickness was measured by inserting a dial gauge equipped with a sharp pin into an intact cartilage layer. The sharp pin penetrated the layer of cartilage, but was stopped by the harder subchondral bone plate. The distance covered by the pin was assumed to be equal to the thickness of the cartilage. For each mammal tested, this measurement was performed on two bone specimens at three different locations.

One specimen of each animal was scanned with a Scanco microCT80 scanner to examine the internal damage caused by the water jet and examine the shape of the drilled holes. This allowed 20 holes to be examined, which was considered sufficient to determine a consistent trend in hole shape. Cartilage tissue damage was examined with a Keyence VHX100 digital microscope equipped with a Keyence VHZ-35 lens.

The actual water pressures were calculated with a custom written Matlab routine. The hole-depth and the cartilage thickness measurements were averaged and rounded off to $0.1 \mathrm{~mm}$. As the adapted dial-gauge measured the combined depth of the hole in the bone and the cartilage, the average thickness of the cartilage layer was subtracted to discriminate between pure bone waterjet drilling and cartilage waterjet drilling. For each specimen, the penetration pressure threshold was determined by the lowest pressure with which a hole depth larger than $0 \mathrm{~mm}$ was drilled.

\section{RESULTS}

Pure waterjets can be used for machining holes in subchondral bone. The minimum-threshold pressure 
for drilling in the subchondral bones of human, goat, sheep and pig calcaneus bone were 37 (SD 10), 36 (SD 5.9), 62 (SD 8.5) and $56 \mathrm{MPa}$ (SD 5.8) respectively (Table 1). In general, the cutting depth increases with pressure (Fig. 3). The gradual rise in depth is most apparent for goat and pig specimens, while sheep and human bone show a more scattered plot.

Observations showed that pressures below the minimum-thresholds caused a continuous waterjet reflection at an angle of approximately 30 degrees to the surface. This induced dents in the cartilage, which were approximately $50 \%$ larger in diameter (from 2 to $3 \mathrm{~mm}$ ) compared to holes that penetrated bone. The reflection angle to the surface increased when the waterjet did penetrate bone. Besides exiting at the hole, water escaped at the sawed-off protrusion (Fig. $2 a$ and 4).
For the majority of the specimens, a pressure of $30 \mathrm{MPa}$ was sufficient to penetrate the cartilage up to the subchondral plate (Table 1). The $\mu \mathrm{CT}$-scans showed consistently that the waterjets create coneshaped holes running from the subchondral plate into trabecular bone (Fig. 4).

\section{DISCUSSION}

The pilot study demonstrated that waterjet drilling with pure waterjets can machine blind holes in articular bone. The minimum water pressure ranged between 36 (average goat) to $62 \mathrm{MPa}$ (average sheep). Variations in minimum water pressure between the animals and between the specimens indicate that one pressure will result in a variance of hole depth. These variations can be caused by differences in bone volume fraction and thicknesses of cartilage, subchondral and trabecular

Table 1. Outcomes of experiment for each mammal calcaneus bone

\begin{tabular}{lcccccc}
\hline & $\begin{array}{c}\text { Average Cartilage } \\
\text { Thickness } \\
{[\mathrm{mm}]}\end{array}$ & $\begin{array}{c}\text { Total number } \\
\text { holes drilled }\end{array}$ & $\begin{array}{c}\text { No holes } \\
\text { (depth of } 0 \mathrm{~mm})\end{array}$ & $\begin{array}{c}\text { Piercing } \\
\text { holes }\end{array}$ & $\begin{array}{c}\text { Immeasurable due to } \\
\text { cavity in bone } \\
(>30 \mathrm{~mm})\end{array}$ & $\begin{array}{c}\text { Average pressure to } \\
\text { penetrate subchondral } \\
\text { plate ([MPa] (SD)) }\end{array}$ \\
\hline Goat & 1.0 & 34 & 5 & 10 & 0 & 36 (SD 5.9) \\
\hline Sheep & 0.8 & 48 & 19 & 2 & 0 & 62 (SD 8.5) \\
\hline Pig & 1.2 & 32 & 15 & 0 & 5 & 56 (SD 5.8) \\
\hline Human & 1.8 & 32 & 10 & 37 (SD 10) \\
\hline
\end{tabular}
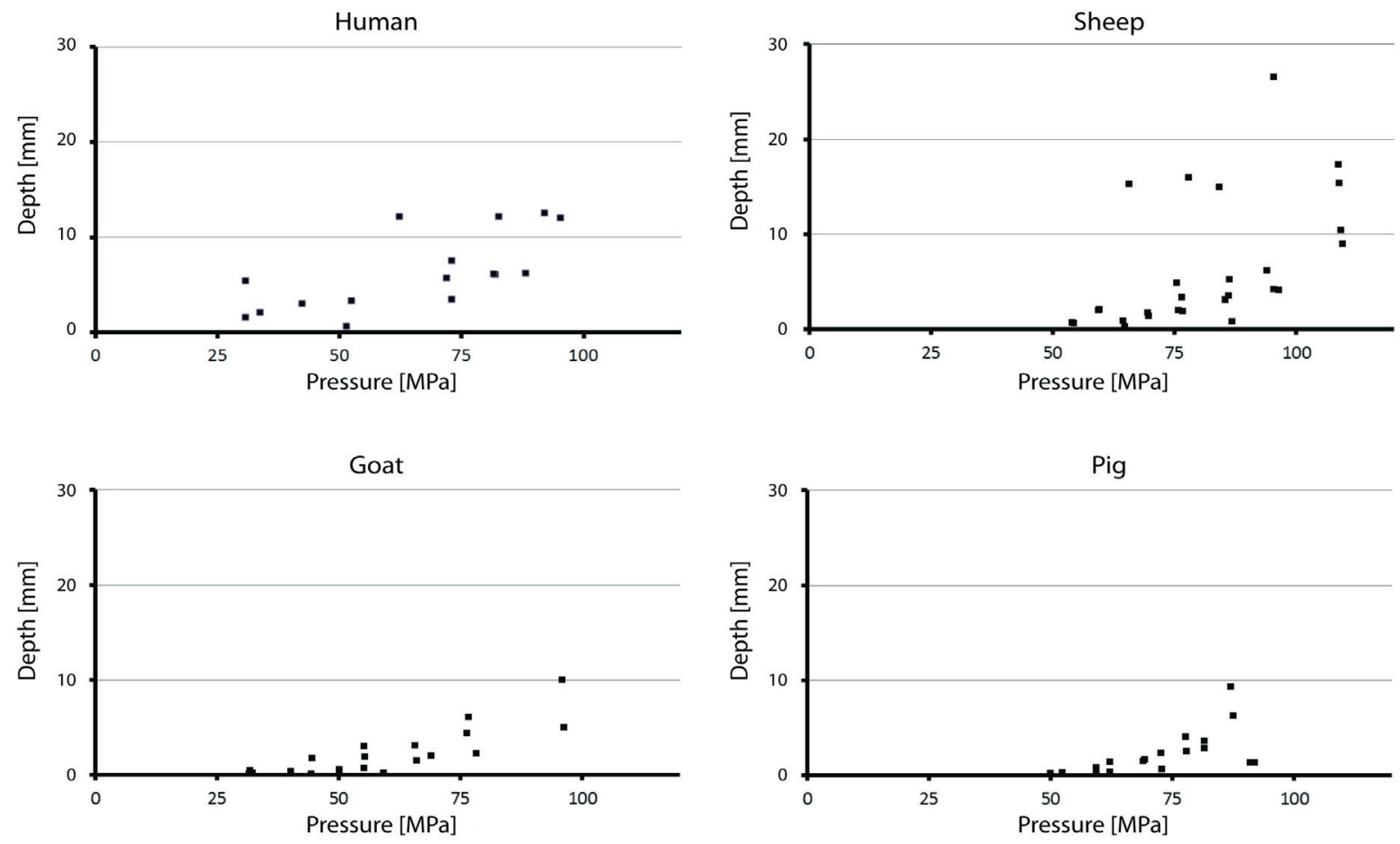

Fig. 3. The outcomes of the waterjet pressure versus the depth of the machined hole for four different mammal calcaneus bones 
bone layers. An increase in bone volume fraction or the thickness of the subchondral bone layer results in stronger bone [32] and [35] that is more resilient to waterjets. For waterjet drilling with similar pressures, human and sheep bone show a larger deviation in hole depth compared to goat and pig specimens (Fig. 3). A possible cause for the larger deviation can be the consistency in origin, forage, treatment and age of the animals, which has a significant influence on the mechanical properties of bone [36] and [37]. The goat and pig bone specimens were acquired from animals nurtured under similar circumstances. For human and sheep cadaveric bone specimens, the age and gender were unknown, thereby contributing to the larger difference in depths for similar pressures.

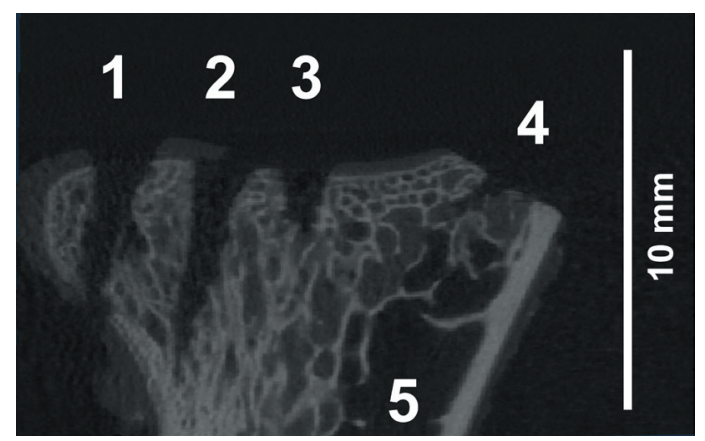

Fig. 4. A slice of a $\mu \mathrm{CT}$ scan with three machined holes; 1) full penetration of the bone, 2) and 3) cone shaped holes, 4) the sawed-off protrusion, and 5) a natural cavity in the bone

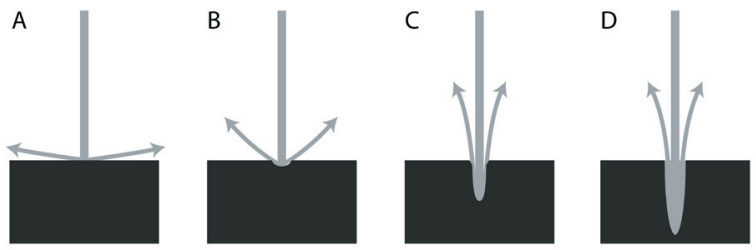

Fig. 5. Different stages of waterjet drilling; a) reflection tangential to the surface, b) small cavity changes reflection angle, c) incoming and outgoing waterjets start to interfere, widening the hole beyond the waterjet diameter, and d) hole depth and diameter are further increased (based on [2], [3], [18] and [19])

The results support Eq. (1), which indicates that an increase of hole depth is expected by an increase of water pressure. Impact pressures, frictional drag and shockwaves are all intensified at higher pressures, which also contribute to the forming of a deeper hole [3] and [38].

The larger dents in the cartilage when the subchondral plate was not penetrated can be explained by the difference in material properties between the bone layers in combination with the reflection angle of the waterjet after impact. During the drilling process, the reflection angle increases with the hole depth (Fig. 5a to d). When the minimal penetration pressure threshold is not met, the energy of the waterjet is insufficient to machine the subchondral plate. Instead of continuing its original path, the water spreads tangentially to the surface (Fig. 5a) [3] and [18], which damages the surrounding cartilage. When the pressure threshold is met, this phenomenon is only present for a split second, thereby leaving a smaller dent.

The four $\mu \mathrm{CT}$ scans gave a view of the shapes of 20 holes that were machined by pure waterjets. This does not allow for generalization, but does demonstrate a consistent trend. The holes showed a decrease in diameter with an increase of depth (Fig. 4). The conical shape of the holes can be explained by the variances in the intensity of the interfering incoming and outgoing water jets. At the top of the hole, the incoming jet enters the water-filled cavity, resulting in disturbances in the water flow and a decrease in the waterjet velocity (Fig. 5). The waterjet's energy is dissipated by pushing the superfluous water towards the circumference and the exit of the hole. This results in a widening of the hole (Figs. $5 \mathrm{c}$ and d). At greater hole depths, the waterjets' energy has been partially dissipated, causing the superfluous water to be pushed out at lower velocities. As a result, the hole diameter at the bottom of a hole increases at a slower pace compared to the shallow depths. This conical shape is potentially useful in orthopedic treatment, such as screw fixation or bone marrow stimulation.

The pre-programmed CNC-controlled nozzle caused some holes to be drilled too close to the rim of the bone, where the bone is thinner than $5 \mathrm{~mm}$. This primarily occurred in the goat bones, which had the smallest dimensions compared to the other calcaneal bones. In these cases, the bone was fully penetrated (piercing hole) and could not be measured (Table 1 , column piercing hole). The missing values of the piercing holes are not considered to have a significant effect on the outcomes of this study. For human specimens, five holes could not be measured because the holes were deeper than the maximum of the $30 \mathrm{~mm}$ that the adapted dial-gauge could measure (Table 1). In these cases, the water pressures were considerably higher than the minimum pressure for penetrating articular bone and therefore do not affect the conclusions of this study. Nevertheless, an increase of the sample size and smaller water pressure increments could have contributed to a higher accuracy in determining the minimum pressure threshold.

The sawed-off protrusion might have caused an increase in hole depth. When a slug of water reaches 
the bottom of a hole, it moves to the path with the least resistance towards an exit. For waterjet drilling in nonporous materials, the primary exit is the hole itself (Figs. 1 and $5 \mathrm{c}$ to d). The open trabecular structure in combination with a sawed-off protrusion allowed the water to leave at a secondary exit, thereby partially removing the interference between the incoming and outgoing jets. Consequently, the drilled holes in this pilot experiment are expected to be deeper than when drilling bone that is complete, which is favorable from the safety point of view.

Fluctuations in the water pressure caused by the intermittently reciprocating plungers [12] may have caused variations in the hole depths, but they were considered marginal compared to the variations in the material characteristics of the bone.

This experiment showed a range of pressures and a resulting range of in depth, which clearly indicates the influence of bone material properties. These results show that pig bone is the most difficult to be machined, which can be considered for future experiments to investigate waterjet settings that can penetrate any type of articular bone. For clinical safety, controlling the depth of a waterjet machined hole is an issue that needs to be addressed. Solely using pressure to control the depth is insufficient due to the heterogeneous characteristics of the bone tissue. To this extent, an additional safety system that shuts off the waterjet after penetrating the suchondral plate is recommended. Nevertheless, piercing bone is unlikely as the majority of the holes in orthopedics are drilled towards the center of a bone where it is thicker.

\section{CONCLUSION}

Machining blind holes in bone by using waterjet technology without adding abrasives is feasible. A minimum pressure threshold needs to be overcome before any damage is inflicted. This threshold differs for every animal tested. A waterjet pressure of 60 MPa is sufficient to inflict damage to the majority of articular bone tissue and should be considered as a starting point for future research. The conical shape of the holes makes pure waterjet drilling in bone a potentially valuable option for orthopaedic treatments.

\section{ACKNOWLEDGEMENTS}

Prof. Dr.-Ing. Fr.-W. Bach, head of the Institute of Materials Science in Hannover, receives our acknowledgement for the use of the facilities at the Water Jet Laboratory Hannover. We are grateful to A.C. Kok, I.N. Sierevelt and J.R.A. Dukker for their help in the preparations of the experiment, statistics and fabrication of experimental equipment, respectively. Finally, we would like to thank Dr. Ir. B. van Rietbergen and Dr. Ir. L. Mulder (Eindhoven University of Technology) for using the $\mu \mathrm{CT}$ scanner and providing $\mu \mathrm{CT}$ imaging related support.

This work was supported by the Technology Foundation Stichting voor de Technologische Wetenschappen (STW), Applied Science Division of NWO, and the technology program of the Ministry of Economic Affairs, The Netherlands (grant number 10851). The sponsor had no involvement in the study design, analysis or interpretation of the data.

\section{REFERENCES}

[1] Hashish, M., Duplessis, M.P. (1978). Theoretical and experimental investigation of continuous jet penetration of solids. Journal of Engineering for Industry-Transactions of the ASME, vol. 100, no. 1, p. 88-94, DOI:10.1115/1.3439351.

[2] Summers, D. (1995). Waterjetting Technology. Taylor \& Francis, London.

[3] Tikhomirov, R.A., Petukhov, E.N., Babanin, V.F., Starikov, I.D., Kovalev, V.A. (1992). High-Pressure Jetcutting. ASME Press, New York.

[4] Cadavid, R., Jean, B., Wustenberg, D. (2009). On the selection of the nozzle geometry and other parameters for cutting corneal flaps with waterjets. Biomedizinische Technik, vol. 54, no. 3, p. 134-141, DOI:10.1515/BMT.2009.017.

[5] Bibbo, C. (2010). VERSAJET (TM) Hydrosurgery technique for the preparation of full thickness skin grafts and the creation of retrograde split thickness skin grafts. Journal of Foot \& Ankle Surgery, vol. 49, no. 4, p. 404-407, DOI:10.1053/j.jfas.2010.04.013.

[6] Tschan, C.A., Keiner, D., Muller, H.D., Schwabe, K., Gaab, M.R., Krauss, J.K., Sommer, C., Oertel, J. (2010). Waterjet dissection of peripheral nerves: An experimental study of the sciatic nerve of rats. Neurosurgery, vol. 67, suppl. 2, p. 368-376, DOI:10.1227/NEU.0b013e3181f9b0c8.

[7] Schmolke, S., Pude, F., Kirsch, L., Honl, M., Schwieger, K., Kromer, S. (2004). Temperature measurements during abrasive water jet osteotomy. Biomedizinische Technik, vol. 49, no. 1-2, p. 18-21, DOI:10.1515/ BMT.2004.004.

[8] Honl, M., Rentzsch, R., Muller, G., Brandt, C., Bluhm, A., Hille, E., Louis, H., Morlock, M., (2000). The use of water-jetting technology in prostheses revision surgery - First results of parameter studies on bone and bone Cement. Journal of Biomedical Materials Research, vol. 53, no. 6, p. 781-790, DOI:10.1002/10974636(2000)53:6<781::AID-JBM20>3.0.CO;2-G.

[9] Honl, M., Rentzsch, R., Schwieger, K., Carrero, V., Dierk, O., Dries, S., Louis, H., Pude, F, Bishop, N., Hille, E., Morlock, M., (2003). The water jet as a new 
tool for endoprosthesis revision surgery - An in vitro study on human bone and bone cement. Bio-Medical Materials and Engineering, vol. 13, no. 4, p. 317-325.

[10] Honl, M., Schwieger, K., Carrero, V., Rentzsch, R., Dierk, O., Dries, S., Pude, F., Bluhm, A., Hille, E., Louis, H.E., Morlock, M., (2003). The pulsed water jet for selective removal of bone cement during revision arthroplasty. Biomedizinische Technik, vol. 48, no. 10, p. 275-280, DOI:10.1515/bmte.2003.48.10.275.

[11] Schwieger, K., Carrero, V., Rentzsch, R., Becker, A., Bishop, C., Hille, E., Louis, H., Morlock, M., Honl, M. (2004). Abrasive water jet cutting as a new procedure for cutting cancellous bone - In vitro testing in comparison with the oscillating saw. Journal of Biomedical Materials Research Part B-Applied Biomaterials, vol. 71B, no. 2, p. 223-228, DOI:10.1002/ jbm.b.10078.

[12] Bach, F.-W., Biskup, C., Kremer, G., Schmolke, S. (2007). Investigation of the AWIJ-drilling process in cortical bone. Proceedings of the 2007 American WJTA Conference and Expo, 1-D.

[13] Hloch, S., Valicek, J., Kozak, D. (2011). Preliminary Results of experimental cutting of porcine bones by abrasive waterjet. Tehnički Vjesnik-Technical Gazette, vol. 18, no. 3, p. 467-470.

[14] Honl, M., Rentzsch, R., Lampe, F., Muller, V., Dierk, O., Hille, E., Louis, H., Morlock, M., (2000). Water jet cutting of bone and bone cement. A study of the possibilities and limitations of a new technique. Biomedizinische Technik, vol. 45, no. 9, p. 222-227, DOI:10.1515/bmte.2000.45.9.222.

[15] Kuhlmann, C., Pude, F., Bishup, C., Krömer, S., Kirsch, L., Andreae, A., Wacker, K., Schmolke, S., (2005). Evaluation of potential risks of abrasive water jet osteotomy in-vivo. Biomedizinische Technik. Biomedical engineering, vol. 50, no. 10, p. 337, DOI:10.1515/BMT.2005.047.

[16] Steadman, J.R., Rodkey, W.G., Rodrigo, J.J. (2001). Microfracture: surgical technique and rehabilitation to treat chondral defects. Clinical Orthopaedics and Related Research, vol. 391, p. S362-369, DOI:10.1097/00003086-200110001-00033.

[17] Asnis, S.E., Kyle, R.F. (1996). Cannulated Screw Fixation: Principles and Operative Techniques. Springer, New York, DOI:10.1007/978-1-4612-2326-9.

[18] Orbanic, H., Junkar, M. (2004). An experimental study of drilling small and deep blind holes with an abrasive water jet. Proceedings of the Institution of Mechanical Engineers Part B-Journal of Engineering Manufacture, vol. 218, no. 5, p. 503-508, DOI:10.1177/095440540421800504.

[19] Ohlsson, L., Ivarson, A., Magnusson, C., Powell, J. (1992). Optimisation of the piercing or drilling mechanism of abrasive water jets. Fluid Mechanics and Its Applications, vol. 13, p. 359-370, DOI:10.1007/97894-011-2678-6_24.

[20] Leach, S., Walker, G. (1966). The application of high speed liquid jets to cutting. Philosophical Transactions of the Royal Society of London, vol. 260A, no. 1110, p. 295-308.

[21] Hashish, M. (1989). An investigation of milling with abrasive-waterjets. Journal of Engineering for Industry-Transactions of the ASME, vol. 111, no. 2, p. 158-166, DOI:10.1115/1.3188745.

[22] Momber, A.W., Kovacevic, R. (1998). Principles of Abrasive Water Jet Machining. Springer, London, DOI:10.1007/978-1-4471-1572-4.

[23] An, Y.H., Draughn, R.A. (2000). Mechanical Testing of Bone and the Bone-Implant Interface. CRC Press, Boca Raton.

[24] Kempson, G.E. (1982). Relationship between the tensile properties of articular cartilage from the human knee and age. Annals of Rheumatic Disseases, vol. 41, no. 5, p. 508-511, DOI:10.1136/ard.41.5.508.

[25] Reilly, D.T., Burstein, A.H. (1975). The elastic and ultimate properties of compact bone tissue. Journal of Biomechanics, vol. 8, no. 6, p. 393-405, DOI:10.1016/0021-9290(75)90075-5.

[26] Burstein, A.H., Reilly, D.T., Martens, M. (1976). Aging of bone tissue: mechanical properties. Journal of Bone and Joint Surgery-American Volume, vol. 58, no. 1, p. 82-86.

[27] Kuhn, J.L., Goldstein, S.A., Ciarelli, M.J., Matthews, L.S. (1989). The limitations of canine trabecular bone as a model for human: A biomechanical study. Journal of Biomechanics, vol. 22, no. 2, p. 95-107, DOI:10.1016/0021-9290(89)90032-8.

[28] Odgaard, A., Hvid, I., Linde, F. (1989). Compressive axial strain distributions in cancellous bone specimens. Journal of Biomechanics, vol. 22, no. 8-9, p. 829-35, DOI:10.1016/0021-9290(89)90066-3.

[29] Athanasiou, K.A., Rosenwasser, M.P., Buckwalter, J.A., Malinin, T.I., Mow, V.C. (1991). Interspecies Comparisons of Insitu Intrinsic Mechanical-Properties of Distal Femoral Cartilage. Journal of Orthopaedic Research, vol. 9, no. 3, p. 330-340, DOI:10.1002/ jor. 1100090304 .

[30] Lane, J.G., Massie, J.B., Ball, S.T., Amiel, M.E., Chen, A.C., Bae, W.C., Sah, R.L., Amiel, D. (2004). Follow-up of osteochondral plug transfers in a goat model: A 6-month study. The American Journal of Sports Medicine, vol. 32, no. 6, p. 1440-50, DOI:10.1177/0363546504263945.

[31] Newman, E., Turner, A.S., Wark, J.D. (1995). The potential of sheep for the study of osteopenia: current status and comparison with other animal models. Bone, vol. 16, no. 4, suppl. p. 277S-284S.

[32] Teo, J.C.M., Si-Hoe, K.M., Keh, J.E.L., Teoh, S.H. (2007). Correlation of cancellous bone microarchitectural parameters from microCT to CT number and bone mechanical properties. Materials Science and Engineering: $C$, vol. 27, no. 2, p. 333-339, DOI:10.1016/j.msec.2006.05.003.

[33] Siu, W., Qin, L., Cheung, W.H., Leung, K. (2004). A study of trabecular bones in ovariectomized goats with micro-computed tomography and peripheral 
quantitative computed tomography. Bone, vol. 35, no. 1, p. 21-26, DOI:10.1016/j.bone.2004.03.014.

[34] Hildebrand, T., Laib, A., Muller, R., Dequeker, J., Ruegsegger, P. (1999). Direct three-dimensional morphometric analysis of human cancellous bone: Microstructural data from spine, femur, iliac crest, and calcaneus. Journal of Bone and Mineral Research, vol. 14, no. 7, p. 1167-1174, DOI:10.1359/ jbmr.1999.14.7.1167.

[35] Bevill, G., Eswaran, S.K., Gupta, A., Papadopoulos, P., Keaveny, T.M. (2006). Influence of bone volume fraction and architecture on computed large-deformation failure mechanisms in human trabecular bone. Bone, vol. 39, no. 6, p. 1218-1225, DOI:10.1016/j.bone.2006.06.016.
[36] Crenshaw, T.D., Peo, E.R. Jr., Lewis, A.J., Moser, B.D., Olson, D. (1981). Influence of age, sex and calcium and phosphorus levels on the mechanical properties of various bones in swine. Journal of Animal Science, vol. 52, no. 6, p. 1319-29.

[37] Zioupos, P., Currey, J.D. (1998). Changes in the stiffness, strength, and toughness of human cortical bone with age. Bone, vol. 22, no. 1, p. 57-66, DOI:10.1016/S8756-3282(97)00228-7.

[38] Chen, L., Siores, E., Wong, W.C.K. (1996). Kerf characteristics in abrasive waterjet cutting of ceramic materials. International Journal of Machine Tools \& Manufacture, vol. 36, no. 11, p. 1201-1206, DOI:10.1016/0890-6955(95)00108-5. 